\title{
Bayesian Estimation and Entropy for Economic Dynamic Stochastic Models: An Exploration of Overconsumption
}

\author{
Amedeo Argentiero* Maurizio Bovi ${ }^{\dagger} \quad$ Roy Cerqueti ${ }^{\ddagger}$
}

\begin{abstract}
This paper examines psycho-induced overconsumption in a dynamic stochastic context. As emphasized by well-established psychological results, these psycho-distortions derive from a decision making based on simple rules-of-thumb, not on analytically sounded optimizations. To our end we therefore compare two New Keynesian models. The first is populated by optimizing Muth-rational agents and acts as the normative benchmark. The other is a "psycho-perturbed" version of the benchmark that allows for the potential presence of overoptimism and, hence, of overconsumption. The parameters of these models are estimated through a Bayesian-type procedure, and performances are evaluated by employing an entropy measure. Such methodologies are particularly appropriate here since they take in full consideration the complexity generated by the randomness of the considered systems. In particular, they let to derive a not negligible information on the size and on the cyclical properties of the biases. In line with cognitive psychology suggestions our evidence shows that the overoptimism/overconsumption is: widespread - it is detected in nation-wide data; persistent - it emerges in full-sample estimations; it
\end{abstract}

\footnotetext{
${ }^{*}$ University of Perugia, Department of Economics.

${ }^{\dagger}$ Italian Institute of Statistics (ISTAT) and University of Rome La Sapienza, Department of Economics and Law. Address: Via Cesare Balbo 16, 00184 Rome, Italy. Tel.: +39 06 46732461. Email: maurizio.bovi@uniroma1.it.

${ }^{\ddagger}$ Corresponding author. University of Macerata, Department of Economics and Law. Address: Via Crescimbeni 20, 62100 Macerata, Italy. Tel.: +39 0733 2583246. Email: roy.cerqueti@unimc.it.
} 
moves according to the expected cyclical behavior - larger in booms, and it disappears in crises. Moreover, by taking into account the effect of these psycho-biases, the model fits actual data better than the benchmark. All considered, then, enhancing the existing literature our findings i) sustain the importance of inserting psychological distortions in macroeconomic models and ii) underline that system dynamics and psycho biases have statistically significant and economically important connections.

JEL code: C30, D58, D80.

Keywords: Dynamic stochastic models, Psychological Biases, Business Cycle, Bayesian Estimation, Entropy. 


\section{Introduction}

Beyond its purely theoretical content, the field of dynamic stochastic models is particularly relevant for applications in several scientific contexts. In fact, such models might be efficiently used to describe the wide set of evolutive phenomena whose dynamics is random. In this respect, economics is one of the most representative subjects where this class of models plays a role of paramount importance (see e.g. Vandewalle and Ausloos, 1998; Ausloos and Ivanova, 2002; Ausloos et al., 2004; Alfarano, et al., 2007; Li and Gao, 2008; Mitchell and Ackland, 2009 and, more recently, Dhesi and Ausloos, 2016; Dhesi et al., 2016).

In this paper we take advantage of the prominent example of New Keynesian theory, which is usually set up as dynamic stochastic general equilibrium (DSGE, in the usual economic jargon) models. Such dynamic models are small-scale settings aimed at formally describing an economic system. DSGE proponents assume that the system is populated by a representative so-called Muthian agent which operates subject to budget constraints and technological restrictions. Specifically, an agent is said to be Muthian if she is able to maximize her utility and to form "rational" - i.e. model-consistent - expectations. Over time these models have become widespread and commonly used because they are a powerful tool that provide a coherent framework for policy discussion and economic analysis. In principle, they can help to identify sources of fluctuations, answer questions about structural changes, forecast the effect of policy changes, etc.

Despite its widespread use, it has long been known that the assumptions behind standard DSGE models are rather stringent. The rational expectations (RE) hypothesis is one important instance. In particular, the RE hypothesis implies that the system can be studied as if a fully-informed optimizing representative decision maker operates in it. The robust results achieved in cognitive psychology - not to mention the simple observation of real -life agents - clearly lowers the realism of standard DSGE models. Indeed, it is unsurprising these models still need to prove their ability to fit actual data, especially in extraordinary cyclical phases.

Our intended contribution and aim is to study the complexity of the typical DSGE model framework when a peculiar kind of perturbation is inserted. 
Specifically, we consider two New Keynesian models. The first, standard, is populated by fully-informed-optimizing Muth-rational agents and acts as the normative benchmark. The other allows the agents' consumption path to be different from the RE one. Throughout the paper we use the adjective "over" exactly to refer to a level of consumption larger than that featuring a Muthrational agent. As mentioned, the motivation to do that is based on well-known results stemming from the theory of heuristics and biases (Kahneman and Tversky 1974). Indeed, cognitive psychology convincingly argues that most agents use intuitive strategies and simple heuristics such as better-than average effects, illusion of control, hindsight bias, confirmation bias and the like. These latter are reasonably effective some of the time, but they also produce biases and give rise to systematic incongruities that are at odds with statistical reasoning and, accordingly, with Muth-rationality. To our ends it is important to underline that these undisputed distortions cannot be derived from "objective" economic reasoning neither from mathematical optimization rules. Otherwise stated they can be seen as drivers of non-analytically based decisions. The rules-of-thumb we study bear other worth noticing features. They are immanent and widespread, in that affecting the representative agent supposed to operate in DSGE models. In addition, the effect of these heuristics on consumption is predictable. First, the persistent distortion is positive - intuitive reasoning generates overoptimism and, in turn, overoptimism leads to overconsumption. Second, economic booms tend to create even more overoptimism than usual. Third, bad economic times tend to make agents more Muth-rational. All that affords us to perform a wellestablished battery of testable hypotheses. The distortion we are interested in has another nice attribute. Ours is a form of psycho-induced overoptimism that, ipso facto, is totally disconnected from economic fundamentals. In this sense we complement the existing macroeconomic literature, which typically approaches psychological issues in a way that is crucially different from ours. In the macroeconomic literature, indeed, psychological issues enters the macroeconomic models, if any, in a very generic way - virtually all authors study "confidence" or "optimism" with no other qualification. By contrast, we examine peculiar psycho-biases with well-established features and we test whether these distortions vary during the cyclical phases. As mentioned, this is crucial 
because it affords us to impose the due discipline to our simulations.

To carry out the analysis, we use methodologies of two types: first, in line with a wide strand of literature (see among others Apte et al., 2007; Canova, 2007; Smets and Wouters, 2007; Farnoosh and Ebrahimi, 2007; Farnoosh and Morteza, 2009; Hutter et al., 2014), we estimate the parameters of the models by applying an inferential Bayesian-type procedure, based on a Monte Carlo Markow Chains (MCMC) algorithm; second, we measure how the performances of the model fits the real data by applying a concept of entropy. For the use of entropy in the measurement of the performances in economic contexts, see e.g. Perazzo et al. (1995), Lorenz and Lohmann (1996), Frigg (2006), Januario et al. (2009), Salarieh and Alasty (2009), Miskiewicz and Ausloos (2010), Sensoy et al. (2014), Bartolacci et al., (2015) and the recent and interesting survey of Tang et al. (2015). The novel approach we propose leads to the assessment of the actual size of the bias. This represents an advancement also in the economicpsychology field of research, which rarely gives indications about the size of these biases. All considered, then, the proposed standpoint could enable us to reach new and intriguing findings.

Supporting our research strategy, evidence shows that taking into account a more realistic modus operandi allows an otherwise standard DSGE model to fit better actual data both in the long-run and in an economic boom scenario. Recessions are instead characterized by more rational decision making. More importantly, all these results are in line with our a priori. One can also note that, to the extent that booms can be seen as "gains", our evidence is also somewhat in line with the prospect theory (Kahneman and Tversky, 1979a).

The rest of the paper is organized as follows. In the next section we deal with psycho-biases and we give support to the overconfidence/overconsumption hypothesis. Section 3 describes the theoretical benchmark model. In section 4 , we provides arguments for inserting the overconfidence hypothesis in a standard DSGE model. In section 5, we describe the empirical data used in our study, the methodology employed to estimate the parameters and the related results. In section 6 , we analyze the model's dynamics through the impulse response functions and we compare the performance of the different model's specifications through the measures of entropy. Section 7 closes the paper. 


\section{Why Do Individuals Overconsume? A brief literature review}

Muth-rationality has been questioned by very many authors. Just to mention, the adaptive learning literature (Evans and Honkapohja, 2001) argues that individuals must relentlessly "learn" to be Muth rational. Somewhat closer to our aim, Agliari, et al. (2015) study a new Keynesian model with heterogeneous agents pointing out that their presence leads to several implications on the dynamic equilibrium properties. Naimzada and Pireddu (2015) examine the interaction of a Keynesian good market and a stock market with biased fundamentalists. A belief bias disposes optimistic agents to overestimate and pessimistic to underestimate the reference value. Their simulations suggest that if the interaction is destabilizing then the model may generate - and explain boom and bust cycles. Alike Gomes (2015), considering a system where individuals are endowed with distinct sentiments, finds persistent endogenous waves of optimism and pessimism. In these models, agents' rationally switch between optimism and pessimism abandoning a belief if it performs poorly. As it should be clear, instead, RE models typically rely on the latent assumption that nonrational agents will not survive a (unspecified) process of evolutionary market competition. Typically, the economic literature dealing with "non-rational" agents does not deepen non-rationality. Instead, unsurprisingly, psychologists such as Kahneman and Tversky (1974) and their numerous followers (Eysenck and Groome, 2015) have examined in depth psychological distortions. The results of their research program on heuristics-and-biases have convincingly shown that most agents use intuitive strategies and simple heuristics such as betterthan-average effects, illusion of control, hindsight bias, confirmation bias and the like. These latter are reasonably effective some of the time, but they also produce biases and give rise to systematic incongruities that are at odds with statistical reasoning and, accordingly, with Muth-rational expectations.

The foregoing offers the motivation to our paper. Indeed, several points need to be underlined here about these undisputed rules-of-thumb. First, these rules do not follow - hence they cannot be derived from - "objective" economic reasoning neither from mathematical optimization rules. Otherwise stated they 
can be seen as drivers of non-analytically based decisions. Second, they are immanent and widespread, in that affecting constantly the representative agent. Third, these heuristics tend to create positive biases in people's decision making. Indeed, it is well-known that most individuals are overconfident about their own relative abilities, and unreasonably optimistic about their future (Camerer and Lovallo, 1999; Sharot, 2011). As Kahneman put it: "The bottom line is that all the biases in judgment that have been identified [by psychologists] in the last fifteen years tend to bias decision-making toward the hawkish side". ${ }^{1}$ Similarly, Shiller (2000, page 142) has argued that "Yet some basic tendency towards overconfidence appears to be a robust human character trait: the bias is definitely toward overconfidence rather than underconfidence." Fourth, a number of intuitive rules contribute to maintain or strengthen overoptimistic beliefs even in the face of contrary evidence. In fact, these heuristics are seen to hamper even the learning by doing, reinforcing the persistence of the positive biases. It is easy to see why the overoptimism stemming from these biases leads to overconsumption.

"Over" here means a level of consumption greater than that of an optimizing agent correctly addressing Euler equations.

The fifth point deals with the possible cyclical features of the psychological distortions here under scrutiny. So far, indeed, we have argued about the structural characteristics of the psycho-biases. Yet another crucial feature of these latter emerges from the following digression. The herd behavior typically emerging during booms (Farmer, 2013) may diffuse rule-of-thumb behaviors even among usually less psycho-prone agents (Milani, 2011; De Grauwe, 2012). Using the famous Mr. Greenspan's words, "irrational exuberance" is at work (see also Shiller, 2000). By the same token, then, one can expect that amid recessions overconsumption could be lowered because of both objective and psychological reasons. Regarding the former, i) in bad periods the cost of erring is higher and ii) the cost of information is lower. Think about the strong media coverage (Curtin, 2003; Doms and Morin, 2004) and the lay agents' greater interest towards financial evolutions during economic crises. This is also somewhat in line with the rational inattention literature (Sims, 2003), which suggests

\footnotetext{
${ }^{1}$ This quotation is reported in Johnson et al. (2006).
} 
that people rationally allocate their attention on salient information only - individuals are less attentive in booms than in bad times. From the psychological viewpoint, then, the theory of depressive realism argues that depressed people tend to be more realistic than "normal" individuals. Alloy and Abramson (1979) and their numerous followers (for a review, see Abramson et al., 2002) have argued that non-depressed people are more likely than depressed people to think that outcomes are contingent on their actions when they are not. They concluded that as opposed to demoralized persons, whose perceptions are apparently accurate, normal people distort reality in an optimistic fashion. The point is that the share of sadden individuals obviously increases in economic turmoil.

On the empirical "out-of-lab" side, Bovi (2009) reports evidence on the enduring presence of these biases throughout two decades and across several European countries. In particular, data confirm that people tend to form systematically overoptimistic predictions and that peculiar cyclical features emerge. A final note refers to the relationships between overoptimism and overconfidence. Although we are aware of the difference between them ${ }^{2}$, in our framework we can consider these terms as equivalent. In fact, results from the existing literature suggest that overoptimism and overconfidence are positively related such that they affect in a similar way the bias we are interested in. In particular, Kahneman and Tversky (1979a, 1979b) demonstrate that human judgment is generally optimistic due to overconfidence. Montier (2007) concludes the overoptimism and overconfidence tend to have the same causes - the illusion of control and the illusion of knowledge. Brunnermeier and Parker (2005) have then argued that, in a consumption-saving example, consumers are both overconfident and overoptimistic. Other studies arguing that overconfidence and overoptimism go hand-in-hand are Koellinger et al. (2007), Abreu and Mendes (2012), Fellner and Krugel (2012). Baker and Nofsinger (2010) offer a recent survey reinforcing the point.

It may also be useful here to recall Brunnermeier and Parker's (2005) argument on overoptimism. Their conclusions on overoptimism are based on the

\footnotetext{
${ }^{2}$ The expectations of optimistic agents are biased toward good outcomes, while overconfident agents overestimate the precision of the signals that they receive.
} 
assumption that people maximize average felicity, optimally balancing this benefit of optimism against the costs of worse decision making. Otherwise stated, they examine distorted expectations while maintaining that agents optimize knowing the correct mapping from actions to payoffs in different states of the world. We draw much more deeply from psychology - our agents are overoptimist not because it is rationale to do that. Their decisions are biased because of a number of unavoidable - in a sense genetic - psychological reasons. Just to mention, the representativeness heuristic and the law of small numbers may explain the excess sensitivity of stock prices as a result of investors' overreacting to (statistically too) short strings of good news (Shleifer, 2000).

To sum up, a number of different biases merges into one single effect that pushes agents toward a systematic overoptimism/overconsumption - when it comes to predicting what will happen in the near or in the distant future, we overestimate the likelihood of positive events, and underestimate the likelihood of negative events. Moreover, the effect of these several biases on overconsumption is enlarged in positive cyclical phases and tend to shrink in bad times. Consumers may be more or less aware about that, but the point remains - a pervasive overoptimism leads individuals to overconsume, especially in objectively rosier stances.

\section{The Theoretical Model}

Dynamic stochastic general equilibrium models are built on microeconomic foundations and emphasize the analytically optimal agents' intertemporal choices. DSGE models are usually organized in three separate but interrelated blocks each modeling the behavior of three representative agents, namely the household, the firm and the policymaker.

The general equilibrium nature of the model captures the interaction between policy actions and agents' behavior. The dependence of current choices on future uncertain outcomes makes the model dynamic and assigns a central role to agents' expectations in the determination of current macroeconomic outcomes. Therefore, e.g., output and inflation tomorrow, and thus their expectations as of today, depend on monetary policy tomorrow in the same way as they do today; 
of course, taking into account what will happen from then on into the infinite future.

The explanation so far refers to the equilibrium aspect of the model. The stochastic nature of the DSGE model allows out-of-equilibrium realizations. Every period random exogenous events perturb the equilibrium conditions, injecting uncertainty in the evolution of the economy and thus generating economic fluctuations. Without these shocks, the economy would evolve along a perfectly predictable path, with neither booms nor recessions. Markup shocks, for example, affect the pricing decisions of the firm that underlies the supply block, while demand shocks capture changes in the willingness of households to purchase the goods produced by the firm.

More specifically, ours is a standard three-blocks new-Keynesian closed economy DSGE model with rational expectations. The demand block captures the representative household's behavior and the government whose public consumption described by an $\mathrm{AR}(1)$ process is entirely financed by lump-sum taxation; the supply block models the representative firm's decisions. In the policy block the key policy variable is the interest rate to reflect the tendency of central banks to raise the short-term interest rate when the economy is overheating as well as when inflation rises, and to lower it in the presence of economic slack. By adjusting the nominal interest rate, monetary policy in turn affects real activity and through it inflation, and eventually the effect acts on the supply block. The policy rule therefore closes the circle, giving us a complete model of the relationship between three key endogenous variables: real output, inflation, and the nominal interest rate.

Clearly, there are several potential candidates for our goals. However, the selected framework is representative of a larger class of models and it is commonly used in both macroeconomic practice and literature. Thus, the version we propose is the result of several validations and refinements. Indeed, our benchmark model is rich enough to provide a satisfactory empirical account of the evolution of output, inflation, and interest rate. All considered, then, the chosen model is a suitable and robust benchmark for our aims.

We are now ready to present more formally the dynamic stochastic model acting in this paper as benchmark (for more details, see Galí, 2003 and 2008, Smets 
and Wouters, 2003 and Galì and Monacelli, 2008).

Expressing all the variables in log-deviations from their steady state values, we have:

$$
\left\{\begin{array}{l}
y_{t}=(1-\lambda) c_{t}+\lambda g_{t} \\
\widetilde{y}_{t}=y_{t}-\bar{y}_{t} \\
\pi_{t}=\beta \pi_{t+1}^{e}+\frac{(1-\theta)(1-\beta \theta)}{\theta} m c_{t} \\
m c_{t}=w_{t}-a_{t} \\
c_{t}=\left(\frac{\alpha}{1+\alpha}\right) c_{t-1}+\left(\frac{1}{1+\alpha}\right) c_{t+1}^{e}-\left(\frac{1-\alpha}{1+\alpha}\right)\left(r_{t}-\pi_{t+1}^{e}\right) \\
w_{t}=\left(\frac{1}{1-\alpha}\right) c_{t}+\gamma n_{t}-\left(\frac{\alpha}{1-\alpha}\right) c_{t-1} \\
n_{t}=y_{t}-a_{t} \\
r_{t}=\phi_{\pi} \pi_{t}+\phi_{y} \widetilde{y}_{t} \\
a_{t}=\rho a_{t-1}+\epsilon_{t}^{a} \\
g_{t}=\varphi g_{t-1}+\epsilon_{t}^{g}
\end{array}\right.
$$

A formal and analytical derivation of each equation of 1 is provided in Appendix.

The subscript $t$ means at time $t, y_{t}$ is current output, $\widetilde{y}_{t}$ is the output gap, $\bar{y}_{t}$ is the fully-flexible price output, $r_{t}$ is the nominal interest rate, $\pi_{t}$ is the inflation rate, $g_{t}$ is the public expenditure, $m c_{t}$ denotes the real marginal cost of firms, $w_{t}$ are real wages, $a_{t}$ is the labor productivity, $n_{t}$ is labor while $c_{t+1}^{e}$ and $\pi_{t+1}^{e}$ denote the rational expectation of variable $c$ and $\pi$ at time $t+1$ formed at time $t$, respectively. The last two equations determine the stochastic dynamics of the labor productivity and public expenditure. The stochastic perturbations $\epsilon_{t}^{a}$ and $\epsilon_{t}^{g}$ are I.I.D.

To be as clear as possible, we have collected the parameters in (1) - along with their economic meanings - in Table 1.

\section{Nesting Heuristics and Biases in the Bench- mark DSGE Model}

In Section 2, we have outlined the reasons why agents may follow biased - with respect to Muth optimality - consumption paths. Taking advantage of psychologists' hints allows drawing a suitable set of hypotheses that we test in this paper. Specifically, we argue - and we verify - the enduring presence of bi- 
Table 1: Definition of the model parameters

\begin{tabular}{|c|c|}
\hline \hline$\lambda$ & steady state government spending share \\
\hline$\alpha$ & persistence in private consumption \\
\hline$\rho$ & persistence of public expenditure \\
\hline$\varphi$ & persistence of labor productivity \\
\hline$\beta$ & rate of time preference \\
\hline$\theta$ & index of price rigidity \\
\hline$\gamma$ & intertemporal elasticity of substitution for leisure (Frisch elasticity) \\
\hline$\phi_{\pi}$ & sensitivity of central bankers to inflation \\
\hline$\phi_{y}$ & sensitivity of central bankers to cyclical stances \\
\hline \hline
\end{tabular}

ases because psychologists convincingly suggest that people use rules of thumb with no sign that they learn. Otherwise stated, when psychological stimuli are taken into account, overconsumption emerges as a persistent feature of agents' decision making, being a structural trait of the human behavior. In fact, it can also be conceptualized that the bias reacts to cyclical phases. Again in a predictable way. It let us to test another two assumptions, offering even more discipline to our exercises. During goldilocks periods, indeed, the agent can be even more optimistic than usual, whereas the negative phases of the business cycle are characterized by more realism. The point is that booms may give rise to larger and more widespread irrational exuberance whereas crises increase the cost of erring and lower the cost of information, leading agents to be more attentive/realistic decision makers. Thus, the other two testable features of our peculiar psycho-biases mentioned before are that i) distortions tend to be larger in booms and ii) to quickly fade out in recessions.

It is worth noting that our definition of psycho-bias is very inclusive without being vague. Indeed, all the psycho distortions stemming from the theory of heuristics and biases point to the same direction - namely, overconsumption. This is a nice feature of these errors because the impact of one or few psychoinduced bias may remain unobserved in the aggregate, whereas the combined effect of several rule-of-thumbs all creating overoptimism/overconfidence may 
have significant system-wide effects. Thus, the overconsumption that we are searching may be driven by all the systematic psycho-driven decision making that explains that part of the business cycle which is typically left unexplained by mainstream rational expectations DSGE models.

In order to introduce the agents' overconsumption into the rational expectations model in (1), this latter needs to be rearranged. One simple and effective way to do so is to add to the standard consumption function an element allowing households to follow both Muth-rational and biased behaviors. More formally, the psycho-biased augmented (PBA) new-Keynesian model we refer to is equal to (1), but for the fact that in the Euler equation modeling the private consumption, $c_{t}$, we insert another expected component:

- Rational expectations (RE) - benchmark: Model (1) with

$$
c_{t}=\left(\frac{\alpha}{1+\alpha}\right) c_{t-1}+\left(\frac{1}{1+\alpha}\right) c_{t+1}^{e}-\left(\frac{1-\alpha}{1+\alpha}\right)\left(r_{t}-\pi_{t+1}^{e}\right)
$$

- Psychological biases (PBA): Model (1) with $\delta>0$

$$
c_{t}=\left(\frac{\alpha}{1+\alpha}\right) c_{t-1}+\left(\frac{1}{1+\alpha}\right) c_{t+1}^{e}+\delta\left|c_{t+1}^{e}\right|-\left(\frac{1-\alpha}{1+\alpha}\right)\left(r_{t}-\pi_{t+1}^{e}\right)
$$

It should be clear that the rationale for inserting this new element derives from the previous discussion about the representative individual tendency toward overconsumption. Here it must be stressed that, unlike the benchmark model, in the PBA one the Euler equation for consumption is not obtained from "objective" optimization rules. In fact, it cannot be derived from mathematical tools almost by definition. The psycho-bias we want to study derives from mental subjective rules-of-thumb which are just at odds with objective reasoning. There are another two reasons to insert the "psycho-perturbing" component to an otherwise optimum path. Firstly, in this way we have an objective benchmark, based on mathematical logic (cf. Appendix) to perturb with subjective, i.e. non analytically-based, decisions. Secondly, the psychological literature we refer to argues that amid recessions the subjective part of the decision making tend to disappear. Or, equivalently, the objective part tend to re-emerge. Hence, all we need is a psychological perturbation and an objective benchmark from which to depart and to which to return according to the 
cyclical phase. The reason why we use the modulus of the expected consumption times delta runs as follows. The behavioral effect must be a non-negative quantity. As $\delta>0$, the use of the modulus ensures to obtain positive values, i.e. overconsumption. Note that the term $\delta$ captures the psycho-bias, whereas the whole term $\delta\left|c_{t+1}^{e}\right|$ aims to capture overconsumption. Thus, the proposed change in the Euler equation allows quantifying both quantities, which are our main empirical objects. We argue then that $\delta$ should interact with the expected consumption because, as recalled, there is an important cyclical component in overoptimism that we want to test. Putting the term $\delta$ as a simple drift in consumption path seems to be insufficient to catch the full effect of overoptimism on overconsumption, which indeed should depend on the level of $c_{t+1}^{e}$. Last but not least, note that the PBA model generalizes the RE one - by construction when $\delta=0$ they are equal.

All considered, then, by letting the data speak within a Bayesian framework (cf. Section 5) we can obtain robust evidence on the size of our parameter of interest.

Given our goal, we examine the two models under three different scenarios:

1. whole sample (the "long run");

2. subsample of economic boom. It is worth recalling that a boom is defined as a time period characterized by positive cyclical output growth, i.e. with $\Delta \ln Y_{t}>0$

3. subsample of economic recessions, i.e.: quarters with $\Delta \ln Y_{t}<0$.

The first exercise allows gathering information on the size of the structural overconsumption, the other two exercises aim at shedding some light on the cyclical behavior of the overconsumption. Altogether they provide a suitable framework to test our hypotheses and the necessary information to address our research goals. 


\section{Dataset, methodology and results of the Bayesian estimation procedure}

The inferential methodology adopted to estimate the model parameters, to simulate and analyze the dynamic behavior of the relevant variables is based on Monte Carlo Markow Chains (MCMC) algorithm, that belongs to the family of Bayesian estimation. We build a multi-chain MCMC procedure based on 4 chains of size 100,000; the algorithm converges within 55,000 iterations to its correct expected value, and, according to these results, we discard the first 55,000 draws from each chain to remove any dependence from the initial conditions.

In detail, our estimation procedure is based on two steps. In the first step, we estimate the mode of the posterior distribution by maximizing the log posterior density function, which is a combination of the prior information on the structural parameters with the likelihood of the data. In the second step, we use the Metropolis-Hastings algorithm in order to draw a complete picture of the posterior distribution and compute the log marginal likelihood of the model. The convergence diagnostic is based on Brooks and Gelman (1998) method.

All of the model computations have been performed using Dynare ${ }^{3}$. Below, we summarize the measurement equations considered, i.e. the relationships between the model variables (on the right side) and the data (on the left side):

$$
\left[\begin{array}{c}
\Delta \ln P_{t} \\
\Delta \ln Y_{t}
\end{array}\right]=\left[\begin{array}{l}
\bar{\pi} \\
\bar{\eta}
\end{array}\right]+100 *\left[\begin{array}{c}
\pi_{t} \\
y_{t}-y_{t-1}
\end{array}\right]
$$

where $P_{t}$ is the personal consumption expenditures' price index, $Y_{t}$ is the real GDP, $\Delta \ln P_{t}=100\left(\ln P_{t}-\ln P_{t-1}\right), \Delta \ln Y_{t}=100\left(\ln Y_{t}-\ln Y_{t-1}\right), \bar{\eta}=$ $100(\eta-1), \bar{\pi}=100\left(\Pi^{*}-1\right)$, where $\eta$ is the real GDP quarterly trend growth rate and $\Pi^{*}$ is the quarterly steady-state inflation rate. The dataset consists of quarterly data for real GDP and personal consumption expenditures' price index referring to the US from 1959q2:2014q1. The source of the data is Federal Reserve Economic Data.

Following the logic of this paper, we have used standard values and distributions

\footnotetext{
${ }^{3}$ Dynare is a software that is freely available from the website http://www.dynare.org and has the ability to simulate and estimate economic models
} 
(see Table 2) for the prior densities of the parameters of the system (1) as suggested by the literature. In particular, we have adopted the mean values, the standard deviations and distributions reported in Smets and Wouters (2007) for the parameters related to the utility function and monetary policy, whereas we have followed real business cycle literature (King and Rebelo, 1999) and Smets and Wouters (2003) for the high persistence in labor productivity and public expenditure. The prior mean value for the steady state government spending share is the average ratio between US real public expenditure and real GDP from $1959 q 2: 2014 q 1$.

In Table 2 we compare prior and posterior distributions of the parameters in the absence of psycho-bias, i.e. $\delta=0$.

Table 2: Prior and Posterior Distribution of Structural Parameters: the benchmark case

\begin{tabular}{|c|c|c|c|c|c|c|c|c|}
\hline \multirow{3}{*}{$\begin{array}{c}\text { Parameter } \\
\alpha\end{array}$} & \multicolumn{3}{|c|}{ Prior distribution } & \multicolumn{5}{|c|}{ Post. distribution } \\
\hline & Distr. Mear & a St. & Dev. & Mode & Mean & Conf. Interval & $95 \%$ & St.Dev. \\
\hline & beta & 0.75 & 0.05 & 0.77 & 0.77 & {$\left[\begin{array}{lll}0.7636 & 0.7689\end{array}\right]$} & 0.01 & \\
\hline$\beta$ & beta & 0.90 & 0.10 & 0.88 & 0.88 & {$\left[\begin{array}{ll}0.8763 & 0.8806\end{array}\right]$} & 0.008 & \\
\hline$\gamma$ & gamma & 2.00 & 0.75 & 2.04 & 2.03 & {$\left[\begin{array}{ll}1.9987 & 2.0559\end{array}\right]$} & 0.15 & \\
\hline$\phi_{\pi}$ & normal & 1.50 & 0.25 & 1.47 & 1.47 & {$\left[\begin{array}{lll}1.4586 & 1.4866\end{array}\right]$} & 0.04 & \\
\hline$\phi_{y}$ & normal & 0.125 & 0.05 & 0.00 & 0.005 & {$\left[\begin{array}{lll}0.0028 & 0.0077\end{array}\right]$} & 0.02 & \\
\hline$\rho$ & beta & 0.975 & 0.10 & 1.00 & 0.999 & {$\left[\begin{array}{lll}0.9971 & 1.0000\end{array}\right]$} & 0.01 & \\
\hline$\varphi$ & beta & 0.90 & 0.05 & 0.97 & 0.973 & {$\left[\begin{array}{lll}0.9723 & 0.9738\end{array}\right]$} & 0.006 & \\
\hline$\lambda$ & beta & 0.26 & 0.05 & 0.22 & 0.22 & {$\left[\begin{array}{ll}0.2121 & 0.2273\end{array}\right]$} & 0.04 & \\
\hline $\bar{\pi}$ & gamma & 0.83 & 0.10 & 0.68 & 0.83 & {$\left[\begin{array}{lll}0.6716 & 0.6836\end{array}\right]$} & 0.01 & \\
\hline $\bar{\eta}$ & normal & 0.76 & 0.10 & 0.77 & 0.78 & {$\left[\begin{array}{lll}0.7749 & 0.7792\end{array}\right]$} & 0.02 & \\
\hline$\theta$ & beta & 0.75 & 0.10 & 0.83 & 0.83 & {$\left[\begin{array}{lll}0.8222 & 0.8327\end{array}\right]$} & 0.02 & \\
\hline$\sigma_{\epsilon^{a}}$ & inv.gamma & 0.10 & 2.00 & 0.02 & 0.02 & {$\left[\begin{array}{lll}0.0176 & 0.0189\end{array}\right]$} & 0.001 & \\
\hline$\sigma_{\epsilon^{g}}$ & inv.gamma & 0.10 & 2.00 & 0.04 & 0.04 & {$\left[\begin{array}{lll}0.0359 & 0.0381\end{array}\right]$} & 0.005 & \\
\hline
\end{tabular}

The posterior values are substantially in line with the prior ones except for the sensitivity of Central Bank to the output gap, that exhibits a strong negative shift, and the index of price rigidity that has a positive shift.

The log-marginal value of the likelihood in this standard case, computed by 
Laplace approximation is -460.38 .

In Table 3, we show prior and posterior distributions of the parameters in the presence of psycho-bias. In this case, the Euler equation of (1) reads as

$$
c_{t}=\left(\frac{\alpha}{1+\alpha}\right) c_{t-1}+\left(\frac{1}{1+\alpha}\right) c_{t+1}^{e}+\delta\left|c_{t+1}^{e}\right|-\left(\frac{1-\alpha}{1+\alpha}\right)\left(r_{t}-\pi_{t+1}^{e}\right)
$$

The prior distribution of the psycho-bias, $\delta$, is assumed to be a gamma with a mean close to zero and unitary standard error. This choice is driven by the overconsumption hypothesis, implying positive values of $\delta$; the almost zeromean ${ }^{4}$ hypothesis allows us to collapse the psycho-bias case to the benchmark one in expected value. Finally, the chosen value of the standard error does not bind the posterior value of $\delta$ in a narrow range.

Table 3: Prior and Posterior Distribution of Structural Parameters: the psycho-bias case

\begin{tabular}{|c|c|c|c|c|c|c|c|}
\hline \multirow[t]{2}{*}{ Parameter } & \multicolumn{3}{|c|}{ Prior distribution } & \multicolumn{4}{|c|}{ Post. distribution } \\
\hline & Distr. Meal & I St. & Dev. & Mode & Mean & Conf. Interval & St.Dev. \\
\hline$\alpha$ & beta & 0.75 & 0.05 & 0.85 & 0.86 & {$\left[\begin{array}{lll}0.8310 & 0.8735\end{array}\right]$} & 0.01 \\
\hline$\beta$ & beta & 0.90 & 0.10 & 1.00 & 0.97 & {$\left[\begin{array}{lll}0.9458 & 1.0000\end{array}\right]$} & 0.04 \\
\hline$\gamma$ & gamma & 2.00 & 0.75 & 2.04 & 2.03 & {$\left[\begin{array}{lll}1.8591 & 2.1629\end{array}\right]$} & 0.06 \\
\hline$\delta$ & gamma & 0.01 & 1.00 & 0.33 & 0.32 & {$\left[\begin{array}{lll}0.0100 & 0.5855\end{array}\right]$} & 0.09 \\
\hline$\phi_{\pi}$ & normal & 1.50 & 0.25 & 1.39 & 1.38 & {$\left[\begin{array}{lll}1.2856 & 1.4718\end{array}\right]$} & 0.04 \\
\hline$\phi_{y}$ & normal & 0.125 & 0.05 & 0.00 & 0.0029 & {$\left[\begin{array}{lll}0.0000 & 0.0063\end{array}\right]$} & 0.01 \\
\hline$\rho$ & beta & 0.975 & 0.10 & 1.00 & 0.999 & {$\left[\begin{array}{lll}0.9957 & 1.0000\end{array}\right]$} & 0.02 \\
\hline$\varphi$ & beta & 0.90 & 0.05 & 0.96 & 0.96 & {$\left[\begin{array}{lll}0.9498 & 0.9679\end{array}\right]$} & 0.005 \\
\hline$\lambda$ & beta & 0.26 & 0.05 & 0.28 & 0.28 & {$\left[\begin{array}{ll}0.2443 & 0.3067\end{array}\right]$} & 0.01 \\
\hline $\bar{\pi}$ & gamma & 0.83 & 0.10 & 0.80 & 0.81 & {$\left[\begin{array}{ll}0.7383 & 0.8724\end{array}\right]$} & 0.02 \\
\hline $\bar{\eta}$ & normal & 0.76 & 0.10 & 0.76 & 0.71 & {$\left[\begin{array}{lll}0.6382 & 0.7778\end{array}\right]$} & 0.02 \\
\hline$\theta$ & beta & 0.75 & 0.10 & 0.89 & 0.89 & {$\left[\begin{array}{lll}0.8816 & 0.8972\end{array}\right]$} & 0.005 \\
\hline$\sigma_{\epsilon^{a}}$ & inv.gamma & 0.10 & 2.50 & 0.03 & 0.03 & {$\left[\begin{array}{lll}0.0218 & 0.0316\end{array}\right]$} & 0.005 \\
\hline$\sigma_{\epsilon^{g}}$ & inv.gamma & 0.10 & 2.40 & 0.03 & 0.03 & {$\left[\begin{array}{lll}0.0255 & 0.0325\end{array}\right]$} & 0.002 \\
\hline
\end{tabular}

The log-marginal value of the likelihood for this case is -417.74. In order to

\footnotetext{
${ }^{4}$ Gamma distribution is not defined for a mean equal to 0 , hence we choose a value very close to but greater than zero (0.01).
} 
compare this scenario $(\delta)$ with the benchmark case $(b)$ we build the Bayes factor through the Laplace method to approximate the integrated likelihood (Kass and Raftery, 1995 and Lewis and Raftery, 1997), that is:

$$
B_{\delta, b}=2 \ln \left[\frac{f\left(\mathbf{Y} \mid M_{P B A}\right)}{f\left(\mathbf{Y} \mid M_{R E}\right)}\right]
$$

where

$$
f\left(\mathbf{Y} \mid M_{m}\right)=\int f\left(\mathbf{Y} \mid \theta_{m}, M_{m}\right) f\left(\theta_{m} \mid M_{m}\right) d \theta_{m} \quad m=P B A, R E
$$

with $M_{P B A}$ and $M_{R E}$ indicating respectively the PBA model and RE model. The Bayes factor is equal to 85.28 , that supports decisively the specification including the psycho-bias parameter. Hence, the PBA model is able to better capture the stylized facts concerning the business cycle.

The posterior value for $\delta$ is significantly different from zero, thus confirming the empirical validity of the psycho-bias hypothesis in the Euler equation.

An intriguing result is that there is a positive shift both in the intertemporal discount factor, $\beta$, and in the consumption persistence parameter, $\alpha$. It means that the psycho bias term is robust in the sense its statistical significance remains despite the presence of other subjective variables, It also implies that taking into account of overconsumption emphasises the presence of greater preference for the future (a higher value of $\beta$ ) and stronger habit formation in consumption (a higher value of $\alpha$ ). Though here less important, the remaining posterior values of the parameters are in line with the benchmark case.

In Table 4, we collect prior and posterior distributions of the parameters for the subsample of economic boom.

To our goal, the most important outcome is that the psycho-bias parameter is still significantly different from zero and, even more importantly, that it is greater than in the "long run" case. Another worth noticing result is that the Bayes factor (equal to 60.92) continue to corroborate the goodness of our PBA model with respect to the $\mathrm{RE}$ one.

Finally, Table 5 deals with the subsample of economic recessions.

The posterior value of the mode of $\delta$ in this case is not statistically different from zero, correctly rejecting the PBA model. Once again, indeed, this result is coherent with our a priori: in bad times people tend to - and have reasons to - perform more objective decision making. 
Table 4: Prior and Posterior Distribution of Structural Parameters: the psycho-bias case with boom

\begin{tabular}{llllllllll}
\hline Parameter & \multicolumn{3}{c}{ Prior distribution } & \multicolumn{5}{c}{ Post. distribution } \\
\hline & Distr. & Mean & St. Dev. & \multicolumn{1}{c}{ Mode } & Mean & Conf. Interval $95 \%$ & St. Dev. \\
\hline$\alpha$ & beta & 0.75 & 0.05 & 0.72 & 0.75 & {$[0.6927$} & $0.8133]$ & 0.003 & \\
$\beta$ & beta & 0.90 & 0.10 & 1.00 & 0.91 & {$[0.7677$} & $1.0000]$ & 0.008 & \\
$\gamma$ & gamma & 2.00 & 0.75 & 1.96 & 1.73 & {$[1.0996$} & $2.5422]$ & 0.08 & \\
$\delta$ & gamma & 0.01 & 1.00 & 3.77 & 2.64 & {$[0.0100$} & $5.0156]$ & 0.13 & \\
$\phi_{\pi}$ & normal & 1.50 & 0.25 & 1.48 & 1.30 & {$[1.0865$} & $1.5993]$ & 0.01 & \\
$\phi_{y}$ & normal & 0.125 & 0.05 & 0.02 & 0.01 & {$[0.0000$} & $0.0131]$ & 0.001 \\
$\rho$ & beta & 0.975 & 0.10 & 0.79 & 0.85 & {$[0.7689$} & $0.9217]$ & 0.005 \\
$\varphi$ & beta & 0.90 & 0.05 & 0.96 & 0.97 & {$[0.9495$} & $0.9809]$ & 0.004 & \\
$\lambda$ & beta & 0.26 & 0.05 & 0.34 & 0.21 & {$[0.1225$} & $0.3012]$ & 0.005 & \\
$\bar{\pi}$ & gamma & 0.83 & 0.10 & 0.77 & 0.71 & {$[0.6311$} & $0.7862]$ & 0.01 & \\
$\bar{\eta}$ & normal & 0.79 & 0.10 & 0.61 & 0.70 & {$[0.5359$} & $0.8289]$ & 0.009 & \\
$\theta$ & beta & 0.98 & 0.10 & 0.83 & 0.84 & {$[0.7943$} & $0.8975]$ & 0.004 & \\
$\sigma_{\epsilon^{a}}$ & inv.gamma & 0.10 & 3.60 & 0.02 & 0.04 & {$[0.0219$} & $0.0617]$ & 0.001 & \\
$\sigma_{\epsilon^{g}}$ & inv.gamma & 0.10 & 2.30 & 0.02 & 0.03 & {$[0.0182$} & $0.0427]$ & 0.002 & \\
\hline
\end{tabular}

The fact that in recessionary periods overconsumption fades out, and rationality takes over is confirmed by the Bayes factor (equal to -222.35) - it strongly supports the model describing Muth-rational agents.

\section{Analysis of the performances}

\subsection{Comparing the models via Impulse Response Func- tions}

In this section we offer i) a preliminary look at the effects on some key macroeconomic variables when a shock hits systems with and without potential overconsumption, and ii) some tentative explanations of the mentioned effects. To learn about how shocks propagate in our two competing systems we exploit a descriptive tool which is typical in the DSGE literature - namely the impulse response 
Table 5: Prior and Posterior Distribution of Structural Parameters: the psycho-bias case with recession

\begin{tabular}{llrllllll}
\hline Parameter & \multicolumn{3}{c}{ Prior distribution } & \multicolumn{5}{c}{ Post. distribution } \\
\hline & Distr. & Mean & St. Dev. & Mode & Mean & Conf. Interval $95 \%$ & St. Dev. \\
\hline$\alpha$ & beta & 0.75 & 0.05 & 0.76 & 0.77 & {$[0.76500 .7793]$} & 0.004 \\
$\beta$ & beta & 0.90 & 0.10 & 0.89 & 0.89 & {$[0.87750 .9030]$} & 0.001 \\
$\gamma$ & gamma & 2.00 & 0.75 & 2.11 & 2.12 & {$[2.0063$ 2.3038] } & 0.001 \\
$\delta$ & gamma & 0.01 & 1.00 & 0.00 & 0.0058 & {$[0.0000$} & $0.0178]$ & 0.03 \\
$\phi_{\pi}$ & normal & 1.50 & 0.25 & 1.54 & 1.52 & {$[1.4856$} & $1.5817]$ & 0.006 \\
$\phi_{y}$ & normal & 0.125 & 0.05 & 0.14 & 0.13 & {$[0.1230$} & $0.1500]$ & 0.003 \\
$\rho$ & beta & 0.975 & 0.10 & 0.96 & 0.94 & {$[0.9355$} & $0.9510]$ & 0.004 \\
$\varphi$ & beta & 0.90 & 0.05 & 0.90 & 0.90 & {$[0.8964$} & $0.9090]$ & 0.002 \\
$\lambda$ & beta & 0.26 & 0.05 & 0.26 & 0.25 & {$[0.2439$} & $0.2677]$ & 0.002 \\
$\bar{\pi}$ & gamma & 1.13 & 0.10 & 1.15 & 1.16 & {$[1.1523$} & $1.1702]$ & 0.003 \\
$\bar{\eta}$ & normal & -0.76 & 0.10 & -0.73 & -0.71 & {$[-0.7338$} & $-0.6943]$ & 0.006 \\
$\theta$ & beta & 0.75 & 0.10 & 0.73 & 0.72 & {$[0.7012$} & $0.7352]$ & 0.004 \\
$\sigma_{\epsilon^{a}}$ & inv.gamma & 0.10 & 2.80 & 0.03 & 0.02 & {$[0.0176$} & $0.0281]$ & 0.003 \\
$\sigma_{\epsilon^{g}}$ & inv.gamma & 0.10 & 0.95 & 0.05 & 0.04 & {$[0.03310 .0524]$} & 0.006 \\
\hline
\end{tabular}

function (IRF). In fact, impulse response functions trace out the response of current and future values of each of the variables to a one-unit increase (or to a one-standard deviation increase) in the current value of one of the system errors, assuming that this error returns to zero in subsequent periods and that all other errors are equal to zero. IRFs summarize model's dynamic properties and, in fact, they are also called dynamic multipliers. In this section we report the IRFs referring to two alternative temporary shocks, one on labor productivity (cf. Fig. 1, with dashed lines referring to the RE model and solid lines to PBA model), the other on public expenditure (cf. Fig. 2, with dashed lines referring to the RE model and solid lines to PBA model). It bears information on the dynamic behavior of the two models. The variables are expressed in logs, thus the measures of the responses can be read as elasticities ${ }^{5}$. In order to highlight

\footnotetext{
${ }^{5}$ The variables responses relate to the posterior values of the parameters and are computed as the dynamic behavior due to a positive shock of size $1 \%$, that is the measure of its standard
} 
the comparison between our two models, in the following figures we plot the IRFs of both models when they are hit by the same (in both qualitative and quantitative terms) shock.

We show only the IRFs for full sample simulations because the IRFs for the two DSGE models under scrutiny are virtually equal for most variables when computed for the subsample characterized by booms and recessions ${ }^{6}$. From the full-sample exercises some facts become apparent. Looking at the two figures as a whole, two common features are that i) the IRFs are qualitatively similar, and that ii) in the long run the two models tend to return to the pre-shock levels. This said, as seen, inserting the psycho-bias term into the otherwise standard model leads to different values of the estimated parameters and, consequently, produce several quantitative differences. In fact, examining separately the effects of supply and demand shock on the two models reveals more details.

When the standard DSGE model is hit by a positive shock to labor productivity, it shows a proportional boost in actual output and a larger expansion in potential output. The latter - which refers to the fully flexible price equilibrium - advances more because of price stickiness (Calvo, 1983). In fact, price stickiness implies that only a fraction of producers lowers the prices following a positive supply shock. In turn, this hampers the growth of private consumption and actual output with respect to the potential one. Accordingly, the output gap (that in this particular case coincides with the employment) as well as the short term nominal interest rate shrinks. The rise in labor productivity and the following fall of labor demand also creates a contraction in real wages. In fact, as the literature has widely shown (Christiano et al. 1992 and Galì, 1999, among the others), price rigidity hampers actual output to increase in the same proportion of the technology shock. Hence, an employment reduction occurs.

Turning the attention to the PBA model, the supply shock scenario points out visible divergence in some variables. In particular, greater productivity now reduces labor demand even more with respect to the standard case. Given the very limited difference between the two models, the logic behind that is always the same: price stickiness. Then, noting that the inflation rate is shocked in a similar way, the smaller employment level leads to a much larger real wage deviation.

${ }^{6}$ These unreported results are available upon request. 
cuts in the PBA model. In spite of this, private consumption does not shrink proportionally - the psycho-induced overconsumption prevents an even larger contraction.

FIG. 1 ABOUT HERE; CAPTION [Impulse response functions for an orthogonalized $1 \%$ shock on labor productivity]

When a positive shock in public expenditure hits the demand-side of the system, private consumption could decrease due to a crowding out effect. Again because of the price rigidity, yet, this latter does not show up. The logic runs as follows. The positive growth of the actual output stemming from the shock generates an increase in employment, real wages and real marginal costs. These latter cause a rise in the inflation rate, but the presence of price stickiness reduces the impact of real marginal costs on inflation, thus generating a smaller rise, with respect to the fully flexible price scenario, in the inflation rate. Therefore, the growth of the nominal interest rate resulting from the greater inflation is lower than in the absence of price stickiness. Accordingly, price stickiness limits the crowding out effect, and the output gap increases. Comparing the two models, the case of the demand shock generates - if any - very small divergences in the dynamics (note the scale). However, there is a worth noting difference in the timing. In the first 60 periods after the shock, PBA private consumption is a bit greater than the standard case. This must be compared with the real wage IRFs, whereas the PBA case presents a higher IRF for just 50 periods. That is to say, again, in good times (output is always positive) heuristics seem to sustain consumption levels over and above objective situations.

FIG. 2 ABOUT HERE; CAPTION [Impulse response functions for an orthogonalized $1 \%$ shock on public expenditure]

So far we have contrasted the relative dynamics of the two models. In the next section we perform another kind of comparison in order to see how much the two models are close to real data. Practically, we examine our two models via an entropy measure that aims to rank our two competing models w.r.t. their ability to fit the statistical features of actual data. This is important in general, but in our setting is even more essential. In fact, this exercise allows supporting the relative realism of the complex systems under scrutiny and, hence, that of the stories they can tell. 


\subsection{Entropy and comparison of the models}

The comparison between the models is performed through measures of entropy. The idea is to measure how the models involved in the "race" fit actual data, analysing the distance between actual data of private consumption, and those stemming from simulating the two competitors. These measures are particularly appropriate for our purposes because they involve the entire empirical distribution of the data under scrutiny. Thus our measure encompasses all information provided by statistics like mean, variance, skewness, kurtosis, autocorrelations at different lags, and so on. This is different with respect to what typically done in the macroeconomic literature where the fitness of DSGE models is based on less general tools such as impulse response functions, standard deviations and correlations. The simulated time series for the RE and PBA models are generated through the MCMC method over the 223 quarters represented in the sample 1959q2:2014q1. For each quarter, we draw 100,000 realizations of the stochastic shocks described and identified in Section 4. Next, we take the expected value of this sequence as the corresponding value for each quarter ${ }^{7}$. The peculiar measure of entropy we use can be briefly described as follows. If we consider a generic sample of real numbers $\left\{x_{1}, x_{2}, \ldots, x_{N}\right\}$, with $N \in \mathbb{N}$, the entropy is given by:

$$
\mathcal{E}=\sum_{k=1}^{N} \frac{\left|x_{k}\right|}{\sum_{j=1}^{N}\left|x_{j}\right|} \cdot \log \left(\frac{\left|x_{k}\right|}{\sum_{j=1}^{N}\left|x_{j}\right|}\right)
$$

Armed with this definition, we compute the reference entropies, i.e. those related to actual data. We denote $\mathcal{E}_{x}$ the reference entropy for the variable $x$, with $x=y, c, \pi$. Then, we calculate the entropies of the simulated series, for both the $\mathrm{RE}$ and the PBA model, as coming out from the estimation of the parameter $\delta$. We denote them as $\mathcal{E}_{x}^{R E}$ (rational expectations) and $\mathcal{E}_{x}^{P B A}$ (psychological biases).

The macroeconomic variables under investigation are viewed as elements of a thermodynamic system, in accord to the Econophysics literature (see the Introduction for some relevant contributions). The model fitting better with the actual data is that whose disorder is closer to the one of the reference sample. Therefore, the absolute value of the difference between the entropies referring

\footnotetext{
${ }^{7}$ Hence, our estimate for each quarter is the average of all the trajectories obtained.
} 
to actual variables $x$ and those referring to the RE model for $x$ represents our three benchmark distances:

$$
d_{x}^{R E}=\left|\mathcal{E}_{x}^{R E}-\mathcal{E}_{x}\right|
$$

Similarly, we measure the distances between the entropy related to $x$ in the cases of the PBA model and those related to actual data:

$$
d_{x}^{\delta}=\left|\mathcal{E}_{x}^{P B A}-\mathcal{E}_{x}\right|
$$

As it should be clear, the PBA model dominates the RE one at the level of variable $x$ if and only if

$$
D_{x}^{\delta, R E}=d_{x}^{\delta}-d_{x}^{R E}<0
$$

The evaluation of the performance through entropies has been implemented for the whole sample of data, for the subsamples of boom and recession.

Table 6 collects the findings, whereas in Table 7 we report the differences in (6) and (7).

\begin{tabular}{|l|c|c|c|}
\hline \hline Real data & Consumption & Inflation & Output \\
\hline ENTIRE SAMPLE & -5.22 & -5.18 & -5.20 \\
\hline SUB-SAMPLE OF BOOM & -5.10 & -5.05 & -5.07 \\
\hline SUB-SAMPLE OF RECESSION & -3.12 & -3.15 & -3.09 \\
\hline \hline RE model & Consumption & Inflation & Output \\
\hline ENTIRE SAMPLE & -5.14 & -5.15 & -5.10 \\
\hline SUB-SAMPLE OF BOOM & -4.55 & -4.44 & -4.46 \\
\hline SUB-SAMPLE OF RECESSION & -4.48 & -4.46 & -4.56 \\
\hline \hline PBA model & Consumption & Inflation & Output \\
\hline ENTIRE SAMPLE & -5.15 & -5.08 & -5.13 \\
\hline SUB-SAMPLE OF BOOM & -4.54 & -4.56 & -4.49 \\
\hline SUB-SAMPLE OF RECESSION & -4.43 & -4.45 & -0.01 \\
\hline
\end{tabular}

Table 6: Entropies for private consumption, inflation and output for the three scenarios considered. 


\begin{tabular}{|l|c|c|c|}
\hline \hline RE model & Consumption & Inflation & Output \\
\hline ENTIRE SAMPLE & 0.08 & 0.03 & 0.10 \\
\hline SUB-SAMPLE OF BOOM & 0.55 & 0.61 & 0.61 \\
\hline SUB-SAMPLE OF RECESSION & 1.36 & 1.31 & 1.47 \\
\hline \hline PBA model & Consumption & Inflation & Output \\
\hline ENTIRE SAMPLE & 0.07 & 0.10 & 0.07 \\
\hline SUB-SAMPLE OF BOOM & 0.56 & 0.49 & 0.58 \\
\hline SUB-SAMPLE OF RECESSION & 1.31 & 1.30 & 3.08 \\
\hline
\end{tabular}

Table 7: Differences between entropies in the RE and PBA cases and the benchmark case. Computations are obtained by using formulas (6) and (7) and the values reported in Table 6 .

The comparison between the values of the entropy measures shows that for the whole sample, PBA model dominates the RE one for consumption and output data with a percentage relative improvement respectively of $12.5 \%$ and $30 \%$. In the sub-sample of boom, the PBA model has a relatively better performance than the $\mathrm{RE}$ one for inflation and output with a percentage relative improvement respectively of almost $20 \%$ and $5 \%$.

Finally, in the case of recession the slight betterment for consumption (3.7\%) and inflation $(0.8 \%)$ of the PBA model compared with RE one is accompanied by a strong worsening for the output of more than $110 \%$.

This evidence confirms the results of the Bayesian estimation process, stating that in a recessive phase of the business cycle individuals are less, if any, prone to overconfidence. In particular, entropies suggest that the disorder of the complex macroeconomic system - with a specific reference to the output gap - is amplified by the addition of the overoptimism term in the new Keynesian model. Differently, in the period of boom, PBA model seems to generally fit the actual data better (or, at least, in a similar way) than the RE one.

Basically, individuals should act as Muthians in bad times, and the overoptimism leading to overconsumption is a specific feature of periods of boom. All in all, the predominance - in terms of explanatory power - of the PBA model on the RE one is debatable, but the way such models describe the real data could 
be well appreciated only by looking at the considered business cycle.

To conclude, it is important to notice that the obtained outcomes allow us to claim the presence of a link between psycho-biases in consumption and the business cycle, even at the level of the single macroeconomic variables.

\section{Concluding Remarks}

In this paper, we elaborate on a new Keynesian DSGE model to support theoretical and empirical evidences on overconsumption. In fact, there are many reasons to believe that real life consumers do not behave as the agent populating standard dynamic stochastic general equilibrium models. In particular, main street individuals are likely to overconsume, in the sense that they follow consumptions path higher than those of optimizing Muth-agents. This leads to think that DSGE models should allow a much larger degree of freedom in agents' decision making.

Two systems are simulated and analyzed through a Bayesian estimation procedure and compared by adopting an entropy approach. Such methodological tools are usually employed in the theory of complex systems, and are particularly appropriate in the context we deal with given the complexity generated by the randomness of the considered models. The benchmark system is tailored on Muth-rational consumers, while the other one includes that agents are allowed - but not obliged - to overconsume with respect to the Muthian one. Our perspective offers the possibility to quantify the actual size of the biases - as well as of their effects on consumption - and to lead to a better fit to the empirical data. In this respect, the Federal Reserve provides official time series related to the quantities of interest. The sample has been explored as a whole and also by taking into account specific subsamples of the business cycle featured by different cyclical phases.

In fact, the size of the overoptimism under scrutiny is likely to show cyclical features. This is so because we refer to very specific psychological distortions that bear more information than the simple and general term "confidence" typically used in the existing literature.

Evidence shows that taking into account the biases stemming from heuris- 
tics allows the DSGE model to fit better actual data. Also, results point out that overconsumption is a structural trait and that booms turn out to enlarge significantly the magnitude of the bias. In bad times, instead, agents show a tendency to be more optimizing/attentive decision makers.

All these empirical outcomes support our research assumptions and enrich both the economic and psychological literature. All in all, they imply i) that the business cycle has a non-trivial psychological content, and ii) that decision making is biased by macroeconomic evolutions in a predictable way. 


\section{References}

[1] Abramson, L.Y., Alloy, L.B., Hankin, B.L., Haeffel, G.J., MacCoon, D.G., Gibb, B.E. (2002). Cognitive vulnerability-stress models of depression in a self-regulatory and psychobiological context. In: I. H. Gotlib, C.L. Hammen (Eds.), Handbook of depression (pp. 268-294). New York: The Guilford Press.

[2] Abreu, M., Mendes, V. (2012). Information, Overconfidence and Trading: Do the Sources of Information Matter?. Journal of Economic Psychology $33(4), 758-775$

[3] Agliari, A., Pecora, N., Spelta, A. (2015). Coexistence of equilibria in a New Keynesian model with heterogeneous beliefs. Chaos, Solitons and Fractals $79,83-95$.

[4] Alfarano, S., Lux, T., Wagner, F., (2007). Empirical validation of stochastic models of interacting agents - A "maximally skewed" noise trader model. European Physical Journal B 55(2), 183-187.

[5] Alloy, L.B., Abramson, L.Y. (1979). Judgment of contingency in depressed and nondepressed students. Sadder but wiser?. Journal of Experimental Psychology 108(4), 441-485.

[6] Apte, A., Hairer, M., Stuart, A.M., Voss, J. (2007). Sampling The Posterior: An Approach to Non-Gaussian Data Assimilation. Physica D: Nonlinear Phenomena 230(1-2), 50-64.

[7] Ausloos, M., Ivanova, K. (2002). Mechanistic approach to generalized technical analysis of share prices and stock market indices. European Physical Journal B 27(2), 177-187.

[8] Ausloos, M., Clippe, P., Pekalski, A. (2004). Model of macroeconomic evolution in stable regionally dependent economic fields. Physica A: Statistical Mechanics and its Applications 337(1-2), 269-287

[9] Baker, K.H., Nofsinger, J.R. (2010). Behavioral Finance: Investors, Corporations, and Markets. John Wiley \& Sons. 
Bartolacci, F., Castellano, N.G., Cerqueti, R. (2015). The impact of innovation on companies' performance: an entropy-based analysis of the STAR Market Segment of Italian Stock Exchange. Technology Analysis and Strategic Management 27(1), 102-123.

[10] Bovi, M. (2009). Economic versus psychological forecasting. Evidence from consumer confidence surveys. Journal of Economic Psychology 30, 563-574.

[11] Brooks, S.P., Gelman A., (1998). General Methods for Monitoring Convergence of Iterative Simulations. Journal of Computational and Graphical Statistics 7(4), 434-55.

[12] Brunnermeier, M.K., Parker, J.A. (2005). Optimal Expectations. American Economic Review 95(4): 1092-1118.

[13] Calvo, G.A. (1983). Staggered Prices in a utility-maximizing framework. Journal of Monetary Economics 12, 383-398.

[14] Camerer, C., Lovallo, D. (1999). Overconfidence and Excess Entry: An Experimental Approach. The American Economic Review 89(1), 306-318.

[15] Canova, F.(2007). Methods for Applied Macroeconomic Research, Princeton University Press.

[16] Christiano, L.J., Eichenbaum, M. (1992) Current Real-Business-Cycle Theories and Aggregate Labor Market Fluctuations. American Economic Review $82(3), 430-50$.

[17] Curtin, R.T. (2003). Unemployment Expectations: The Impact of Private Information on Income Uncertainty. Review of Income and Wealth 49(4), 539-554.

[18] De Grauwe, P. (2012). Booms and busts: new Keynesian and behavioural explanations. In: Solow, Robert M. and Touffut, Jean-Philippe, (eds.) What's Right With Macroeconomics? The Cournot Centre series. Edward Elgar Publishing Ltd, Cheltenham, 149-180.

Dhesi, G., Shakeel, M., Xiao, L. (2016) Modified Brownian Motion Approach to Modelling Returns Distribution. Wilmott Magazine, forthcoming. Available at http://arxiv.org/abs/1507.02203. 
[19] Dhesi, G., Ausloos, M. (2016) Modelling and Measuring the Irrational behaviour of Agents in Financial Markets: Discovering the Psychological Soliton. Chaos, Solitons and Fractals doi:10.1016/j.chaos.2015.12.015.

[20] Doms, M., Morin, N. (2004). Consumer sentiment, the economy, and the news media, finance and economics discussion series, Vol. 51. Washington, DC: Divisions of Research and Statistics and Monetary Affairs Federal Reserve Board.

[21] Eysenck, M.W. and Groome, D. (2015). Cognitive Psychology: Revisiting the Classic Studies, SAGE Publishing

[22] Evans and Honkapohja (2001). Learning and expectations in macroeconomics. Princeton University Press.

[23] Farmer, R.E.A. (2013). "Animal Spirits, Persistent Unemployment and the Belief Function" in Roman Frydman and Edmund Phelps (eds), Rethinking Expectations: The Way Forward for Macroeconomics, Princeton University Press, 251-276.

[24] Farnoosh, R., Ebrahimi, M. (2007). Monte Carlo method via a numerical algorithm to solve a parabolic problem. Applied Mathematics and Computation 190(2), 1593-1601.

[25] Farnoosh, R., Morteza, E. (2009). Monte Carlo simulation for solving Fredholm integral equations. Kybernetes 38(9), 1621-1629.

[26] Fellner, G., Krügel, S. (2012). Judgmental overconfidence: Three measures, one bias?. Journal of Economic Psychology 33(1), 142-154.

[27] Frigg, R., (2006). Chaos and randomness: An equivalence proof of a generalized version of the Shannon entropy and the Kolmogorov-Sinai entropy for Hamiltonian dynamical systems. Chaos, Solitons and Fractals 28(1), 26-31.

[28] Galì, J. (1999). Technology, Employment, and the Business Cycle: Do Technology Shocks Explain Aggregate Fluctuations? American Economic Review 89(1), 249-271. 
[29] Galì, J. (2003), New Perspectives on Monetary Policy, Inflation, and the Business Cycle. In: M. Dewatripont, L. Hansen, and S. Turnovsky (Eds.). Advances in Economic Theory, Vol. III (pp. 151-197). Cambridge University Press.

[30] Galì, J. (2008), Monetary Policy, Inflation and the Business Cycle, Princeton University Press.

[31] Galì, J., Monacelli, T. (2008). Optimal Monetary and Fiscal Policy in a Currency Union. Journal of International Economics 76(1), 116-132.

[32] Gomes O. (2015) Sentiment cycles in discrete-time homogeneous networks Physica A: Statistical Mechanics and its Applications 428, 224-238.

[33] Hutter, A., Wootton, J. R. and Loss, D. (2014). Efficient Markov chain Monte Carlo algorithm for the surface code. Physical review A: Atomic, Molecular, and Optical Physics 89(2), 022326.

[34] Januario, C., Gracio, C., Duarte, J., (2009). Measuring complexity in a business cycle model of the Kaldor type. Chaos, Solitons and Fractals 42(5), 2890-2903.

[35] Kahneman, D., Tversky, A. (1974). Judgment under uncertainty: Heuristics and biases. Science 185, 1124-1131.

[36] Kahneman, D., Tversky, A. (1979a). Prospect theory: An analysis of decisions under risk. Econometrica 47, 313-327.

[37] Kahneman, D., Tversky, A. (1979b). Intuitive prediction: Biases and corrective procedures. In: S. Makridakis \& S. C. Wheelwright (Eds.) Studies in the Management Sciences: Forecasting. Amsterdam: North Holland.

[38] Kass, R.E., Raftery, A.E. (1995). Bayes Factors. Journal of the American Statistical Association 90(430), 791.

[39] King, R. G., Rebelo, S. T. (1999). Resuscitating real business cycles, in Taylor, J. B., Woodford, M. (eds): Handbook of Macroeconomics, edition 1, vol. 1, chapter 14, 927-1007. Elsevier. 
[40] Koellinger P., Minniti, M., Schade, C. (2007). I think I can, I think I can: Overconfidence and entrepreneurial behavior. Journal of Economic Psychology 28(4), 502-527.

[41] Lewis, S.M., Raftery, A.E. (1997). Estimating Bayes factors via posterior simulation with the Laplace-Metropolis estimator. Journal of the American Statistical Assocation 92, 648-655.

[42] Li, H., Gao, Y., (2008). A GDP fluctuation model based on interacting firms. Physica A: Statistical Mechanics and its Applications 387(21), 52255230 .

[43] Lorenz, H.W., Lohmann, M., (1996). On the role of expectations in a dynamic Keynesian macroeconomic model. Chaos, Solitons and Fractals $7(12), 2135-2155$.

[44] Miskiewicz, J., Ausloos, M., (2010). Has the world economy reached its globalization limit?. Physica A: Statistical Mechanics and its Applications $389(4), 797-806$.

[45] Mitchell, L., Ackland, G.J., (2009). Boom and bust in continuous time evolving economic model. European Physical Journal B 70, 567-573.

[46] Milani, F. (2011). Expectation Shocks and Learning as Drivers of the Business Cycle. Economic Journal 121(552), 379-401.

[47] Montier, J. (2007). Behavioral Investing. Wiley Finance.

[48] Naimzada, A.K., Pireddu, M., (2015). Real and financial interacting markets: A behavioral macro-model, Chaos, Solitons and Fractals 77, 111-131.

[49] Perazzo, R.P.J., Reich, S.L., Schvarzer, J., Virasoro, M.A., (1995). Inflation and relaxation to equilibrium in a complex economic system. Chaos, Solitons and Fractals 6, 455-470.

[50] Salarieh, H., Alasty, A., (2009). Chaos control in an economic model via minimum entropy strategy. Chaos, Solitons and Fractals 40(2), 839-847

[51] Sensoy, A., Sobaci, C., Sensoy, S., Alali, F., (2014). Effective transfer entropy approach to information flow between exchange rates and stock markets. Chaos, Solitons and Fractals 68, 180-185. 
[52] Sharot, T. (2011). The Optimism Bias: A Tour of The Irrationally Positive Brain, Pantheon Books

[53] Shiller, R. (2000). Irrational exuberance. Princeton: Princeton University Press.

[54] Shleifer, A. (2000). Clarendon Lectures: Inefficient Markets. Oxford University Press.

[55] Sims, C. (2003). Implications of rational inattention. Journal of Monetary Economics 50 (3), 665-690

[56] Smets, F., Wouters, R. (2003). An Estimated Dynamic Stochastic General Equilibrium Model of the Euro Area. Journal of the European Economic Association 1(5), 1123-1175.

[57] Smets, F., Wouters, R. (2007). Shocks and Frictions in US Business Cycles: A Bayesian DSGE Approach. American Economic Review 97(3), 586-606.

[58] Tang, L., Lv, H., Yang, F., Yu, L., (2015). Complexity testing techniques for time series data: A comprehensive literature review. Chaos, Solitons and Fractals 81(A), 117-135.

[59] Vandewalle, N., Ausloos, M., (1998). Multi-affine analysis of typical currency exchange rates. European Physical Journal B 4(2), 257-261 


\section{Appendix}

\section{The Analytical Derivation of the Baseline Theoretical Model}

\section{Households}

The economy is populated by an infinitely-lived representative household with preferences defined over current private consumption, $C_{t}$, relative to a constant proportion $(\alpha)$ to the aggregate past consumption (Smets and Wouters, 2003), $C_{t-1}$, public consumption, $G_{t}$ and labor services, $N_{t}$, aimed at maximizing the expected discounted value of an intertemporal utility function, i.e.:

$$
E_{0} \sum_{t=0}^{\infty} \beta^{t} U_{t}\left(\left(C_{t}-\alpha C_{t-1}\right), G_{t}, N_{t}\right)
$$

with $\beta^{t}$ corresponding to the subjective discount factor, under the following intertemporal budget constraint:

$$
P_{t} C_{t}+E_{t}\left\{Q_{t, t+1} D_{t+1}\right\} \leq D_{t}+W_{t} N_{t}+T_{t}
$$

where $D_{t+1}$ is the nominal in $t+1$ payoff for a generic financial activity held at the end of period $t, Q_{t, t+1}$ is the stochastic discount factor for one-period ahead nominal payoffs, $P_{t}$ is the consumer price index, $W_{t}$ are nominal wages and $T_{t}$ indicates lump-sum taxation that entirely finances government spending $G_{t}$.

In particular $C_{t}$ is defined as follows

$$
C_{t}=\left[\int_{0}^{1} C_{t}(i)^{1-\frac{1}{\varepsilon}} d i\right]^{\frac{\varepsilon}{\varepsilon-1}}
$$

with $i$ representing the variety of goods produced by each firm acting as a monopolistic competitor, $C_{t}(i)$ is the consumption of the good $i$ and $\varepsilon$ indicating the elasticity of substitution between differentiated goods.

The optimal allocation of expenditures across the households reads as

$$
C_{t}(i)=\left(\frac{P_{t}(i)}{P_{t}}\right)^{-\varepsilon} C_{t}
$$

with $P_{t}(i)$ representing the price of the good $i$ and implying that

$$
\int_{0}^{1} P_{t}(i) C_{t}(i) d i=P_{t} C_{t}
$$


and

$$
P_{t}=\left[\int_{0}^{1} P_{t}(i)^{1-\varepsilon} d i\right]^{\frac{1}{1-\varepsilon}}
$$

The period utility function assumes the following semi-logarithmic form:

$$
U\left(\left(C_{t}-\alpha C_{t-1}\right), G_{t}, N_{t}\right)=(1-\zeta) \log \left(C_{t}-\alpha C_{t-1}\right)+\zeta \log G_{t}-\frac{N_{t}^{1+\gamma}}{1+\gamma}
$$

where $\zeta$ is the share of public consumption in the utility function.

The problem is solved by using the method of Lagrange multipliers ${ }^{8}$, i.e.:

$$
L=\max _{\left[C_{t}, N_{t}, D_{t+1}\right]_{t=0}^{\infty}} E\left[\begin{array}{c}
\sum_{t=0}^{\infty} \beta^{t}\left((1-\zeta) \log \left(C_{t}-\alpha C_{t-1}\right)+\zeta \log G_{t}-\frac{N_{t}^{1+\gamma}}{1+\gamma}\right)+ \\
+\chi_{t}\left(D_{t}+W_{t} N_{t}+T_{t}-P_{t} C_{t}-E_{t}\left\{Q_{t, t+1} D_{t+1}\right\}\right)
\end{array}\right]
$$

where $\chi_{t}$ is the dynamic Lagrange multiplier, with the following three necessary conditions:

$$
\begin{aligned}
\frac{\partial L}{\partial C_{t}} & : \frac{(1-\zeta)}{\left(C_{t}-\alpha C_{t-1}\right) P_{t}}=\chi_{t} \\
\frac{\partial L}{\partial N_{t}} & : \frac{N_{t}^{\gamma}}{W_{t}}=\chi_{t} \\
\frac{\partial L}{\partial D_{t+1}} & : E_{t}\left\{Q_{t, t+1}\right\} \chi_{t}=\beta E_{t} \chi_{t+1} \Rightarrow \chi_{t}=\frac{\beta E_{t}}{E_{t}\left\{Q_{t, t+1}\right\}} \chi_{t+1}
\end{aligned}
$$

where (17) states that in equilibrium the value of marginal utility of consumption at time $t$ is equal to the discounted expected value of marginal utility of consumption at time $t+1$.

The following equation is a result of the combination of (15) and (16), i.e.:

$$
N_{t}^{\gamma}\left(C_{t}-\alpha C_{t-1}\right)=\frac{W_{t}}{P_{t}}(1-\zeta)
$$

Equation (18) can be re-written in its steady state version, where the upperbar superscript on a variable indicates the steady state value:

$$
\frac{\bar{C} \bar{N} \bar{P}}{\bar{W}(1-\zeta)}-\alpha \frac{\bar{C} \bar{N} \bar{P}}{\bar{W}(1-\zeta)}=1
$$

Now, using the following first-order approximation:

$$
X_{t} Y_{t} \simeq \bar{X} \bar{Y}\left(1+\hat{x}_{t}+\hat{y}_{t}\right)
$$

\footnotetext{
${ }^{8}$ The use of dynamic programming technique would produce the same results.
} 
where $\hat{x}_{t}=x_{t}-\bar{x}$ and $\hat{y}_{t}=y_{t}-\bar{y}$ indicate the log-deviation of the variable from its steasy state value, equation (18) can be similarly log-linearized around the steady state:

$$
\begin{aligned}
\frac{\bar{C} \bar{N}^{\gamma} \bar{P}}{\bar{W}(1-\zeta)}\left(1+\hat{c}_{t}+\gamma \hat{n}_{t}+\hat{p}_{t}-\hat{w}_{t}\right)-\alpha \frac{\bar{C} \bar{N} \bar{P}}{\bar{W}(1-\zeta)}\left(1+\hat{c}_{t-1}+\gamma \hat{n}_{t}+\hat{p}_{t}-\hat{w}_{t}\right) & =1 \\
\hat{c}_{t}+\gamma \hat{n}_{t}+\hat{p}_{t}-\hat{w}_{t}-\alpha \hat{c}_{t-1}-\alpha \gamma \hat{n}_{t}-\alpha \hat{p}_{t}+\alpha \hat{w}_{t} & =0 \\
\left(\frac{1}{1-\alpha}\right) \hat{c}_{t}+\gamma \hat{n}_{t}-\left(\frac{\alpha}{1-\alpha}\right) \hat{c}_{t-1}+\hat{p}_{t} & =\hat{w}_{t}
\end{aligned}
$$

The last expression states that a positive increase in real wages ${ }^{9}\left(\hat{w}_{t}-\hat{p}_{t}\right)$ determines a positive growth of consumption $\hat{c}_{t}$ and labor supply $\hat{n}_{t}$. Nevertheless, the presence of habit formation in consumption $(\alpha>0)$ generates an adjustment cost in consumption, thus weakening the increase in consumption when real wages raise.

The combination of (15) and (17) reads as:

$$
\beta R_{t} E_{t}\left[\left(\frac{C_{t}-\alpha C_{t-1}}{C_{t+1}-\alpha C_{t}}\right)\left(\frac{P_{t}}{P_{t+1}}\right)\right]=1
$$

where $R_{t}=\frac{1}{E_{t}\left\{Q_{t, t+1}\right\}}$ is the gross nominal interest rate.

Following the same procedure of (18), (21) can be conveniently log-linearized around the steady state, which states that

$$
\bar{R}=\frac{1}{\beta}
$$

The log-linearization of $(21)$ reads as:

$$
\begin{aligned}
\frac{1}{\bar{R} \beta}\left[\begin{array}{c}
1+\hat{c}_{t+1}^{e}+\hat{p}_{t+1}^{e}-\alpha\left(\hat{c}_{t}+\hat{p}_{t+1}^{e}\right)-\hat{c}_{t}-\hat{p}_{t}-r_{t}+ \\
\alpha\left(\hat{c}_{t-1}+\hat{p}_{t}+r_{t}\right)
\end{array}\right] & =1 \\
\frac{\alpha}{1+\alpha} \hat{c}_{t-1}+\left(\frac{1}{1+\alpha}\right) \hat{c}_{t+1}^{e}-\left(\frac{1-\alpha}{1+\alpha}\right)\left(r_{t}-\hat{\pi}_{t+1}^{e}\right) & =\hat{c}_{t}
\end{aligned}
$$

with $\pi_{t+1}^{e}=p_{t+1}^{e}-p_{t}$. This is the $\log$-linearized form of the Eurler equation in the presence of habit formation in consumption $(\alpha>0)$, which states that the growth of current consumption is positively related to a persistence effect of lagged consumption $\hat{c}_{t-1}$, according to the coefficient $\frac{\alpha}{1+\alpha}$, to the expected increase in future consumption $\hat{c}_{t+1}^{e}$ (weakened with respect to the case of absence of any habit formation by the coefficient $\left.\frac{1}{1+\alpha}\right)$ and negatively related to the real interest rate $\left(r_{t}-\hat{\pi}_{t+1}^{e}\right)$. In fact, a positive growth of this latter quantity determines a decrease in private consumption in favor of saving.

\footnotetext{
${ }^{9}$ In order to reduce the equations in (1) we indicate real wages in a more compacted form with $w$.
} 


\section{Firms}

The supply side of the economy is composed of a continuum of firms, indexed by $i \epsilon[0 ; 1]$; each firm produces a different variety of good with the same constant returns to scale technology, i.e.

$$
Y_{t}(i)=A_{t} N_{t}(i)
$$

where $Y_{t}(i)$ is the production function of good $i, N_{t}(i)$ is the amonunt of labor employed in the productive process of good $i$ and $A_{t}$ is a productivity shifter whose law of motion in logs reads as

$$
a_{t}=\rho a_{t-1}+\epsilon_{t}^{a}
$$

where $a_{t}=\log A_{t}, \rho \epsilon[0,1]$ is the persistence coefficient of labor productivity and $\epsilon_{t}^{a}$ is a white noise.

Each firm has a probability of resetting price in any given period, $1-\theta$, independent across firms (staggered price setting, Calvo (1983)), with $\theta \epsilon[0 ; 1]$, indicating an index of price stickiness. Hence, the implied average price duration is $\frac{1}{1-\theta}$.

Labor market clearing condition reads as

$$
\begin{aligned}
N_{t} & =\int_{0}^{1} N_{t}(i) d i \\
N_{t} & =\int_{0}^{1} \frac{Y_{t}(i)}{A_{t}} d i \\
N_{t} & =\left(\frac{Y_{t}}{A_{t}}\right) \int_{0}^{1}\left(\frac{P_{t}(i)}{P_{t}}\right)^{-\varepsilon} d i
\end{aligned}
$$

The first-order log-linearization of $(27)$ is ${ }^{10}$

$$
y_{t}=a_{t}+n_{t}
$$

The definition of real marginal costs $\left(m c_{t}\right)$ reads as

$$
m c_{t}=w_{t}-p_{t}-a_{t}
$$

The aggregate price dynamics reads as

$$
P_{t}=\left[\theta\left(P_{t-1}\right)^{1-\varepsilon}+(1-\theta)\left(P_{t}^{*}\right)^{1-\varepsilon}\right]^{\frac{1}{1-\varepsilon}}
$$

\footnotetext{
${ }^{10}$ The lowercase variables indicate the corresponding log-linear format. When the non linear version of an equation contains only multiplicative terms the log-linearized equation, which coincides with the log-deviation around the steady state, is not an approximation.
} 
with $P_{t}^{*}$ indicating the prices resetted in period $t$.

The division of each member of (30) by $P_{t-1}$ reads as

$$
\Pi_{t}^{1-\varepsilon}=\theta+(1-\theta)\left(\frac{P_{t}^{*}}{P_{t-1}}\right)^{1-\varepsilon}
$$

The log-linearization of (31) around zero inflation steady state produces the following equivalent results

$$
\begin{aligned}
& \pi_{t}=(1-\theta)\left(p_{t}^{*}-p_{t-1}\right) \\
& p_{t}=\theta p_{t-1}+(1-\theta) p_{t}^{*}
\end{aligned}
$$

A firm in period $t$ chooses a price $P_{t}^{*}$ that maximizes the current market value of the profits $\Upsilon_{t}$, i.e.

$$
\max _{P_{t}^{*}} \sum_{k=0}^{\infty} \theta^{k} E_{t}\left\{Q_{t, t+k}\left(P_{t}^{*} Y_{t+k \mid t}-\Psi_{t+k}\left(Y_{t+k \mid t}\right)\right)\right\}
$$

subject to the sequence of demand constraints

$$
Y_{t+k \mid t}=\left(\frac{P_{t}^{*}}{P_{t+k}}\right)^{-\varepsilon} C_{t+k}
$$

for $k=0,1,2, \ldots$ and where $Q_{t, t+k}=\beta^{k}\left(C_{t+k} / C_{t}\right)\left(P_{t} / P_{t+k}\right)$ is the discount factor, $\Psi_{t}(\cdot)$ is the cost function of the firm, whereas $Y_{t+k \mid t}$ represents output in period $t+k$ for a firm resetting its price in period $t$. Next, the first order condition associated with the problem (34) is given by:

$$
\sum_{k=0}^{\infty} \theta^{k} E_{t}\left\{Q_{t, t+k} Y_{t+k \mid t}\left(P_{t}^{*}-M \psi_{t+k \mid t}\right)\right\}=0
$$

where $\psi_{t+k \mid t}=\Psi_{t+k}^{\prime}\left(Y_{t+k \mid t}\right)$ indicates the nominal marginal cost in period $t+k$ for a firm resetting its price in period $\mathrm{t}$ and $M=\frac{\varepsilon}{\varepsilon-1}$ that is the desired markup in the absence of constraints on the frequency of price adjustment. Note that in the absence of price rigidities $(\theta=0)$ the previous condition collapses to the optimal price setting condition under flexible prices:

$$
P_{t}^{*}=M \psi_{t \mid t}
$$

Then, the division of both the members of (36) by $P_{t-1}^{i}$ reads as:

$$
\sum_{k=0}^{\infty} \theta^{k} E_{t}\left\{Q_{t, t+k} Y_{t+k \mid t}\left(\frac{P_{t}^{*}}{P_{t-1}}-M * M C_{t+k \mid t} \Pi_{t-1, t+k}\right)\right\}=0
$$


where $M C_{t+k \mid t}=\frac{\psi_{t+k \mid t}}{P_{t+k}}$ is the real marginal cost in period $t+k$ for firms whose last price set is in period $t$.

Finally, the log-linearization of (38) around the zero inflation steady state with a first-order Taylor expansion reads as

$$
p_{t}^{*}-p_{t-1}=(1-\beta \theta) \sum_{k=0}^{\infty}(\beta \theta)^{k} E_{t}\left[\widehat{m c}_{t+k \mid t}+\left(p_{t+k}-p_{t-1}\right)\right]
$$

where $\widehat{m c}_{t+k \mid t}=m c_{t+k \mid t}-\overline{m c}$ is the log-deviation of marginal cost from its steady state value.

The optimal price setting strategy for the typical firm resetting its price in period $t$ can be derived from (39), after some algebra:

$$
p_{t}^{*}=\mu+(1-\beta \theta) \sum_{k=0}^{\infty}(\beta \theta)^{k} E_{t}\left[m c_{t+k \mid t}+p_{t+k}\right]
$$

with $\mu=\log \frac{\varepsilon}{\varepsilon-1}$, that represents the optimal markup in the absence of constraints on the frequency of price adjustment $(\theta=0)$. The level of output associated to a fully-flexible price scenario is $\bar{y}_{t}$ with the following corresponding log-linear definition of output gap

$$
\tilde{y}_{t}=y_{t}-\bar{y}_{t}
$$

Hence, the price setting rule for the firms resetting their prices is represented by a charge over the optimal markup in the presence of fully flexible prices, given by a weighted average of their current and expected nominal marginal costs, with the weights being proportional to the probability of the price remaining effective $(\theta)^{k}$.

Note that, under the hypothesis of costant returns to scale, implicit in the production function of our model, the marginal cost is independent from the level of production, i.e. $m c_{t+k \mid t}=m c_{t+k}$ and, hence, common across firms; so, the expression (40) can be rewritten in the following way:

$$
p_{t}^{*}-p_{t-1}=(1-\beta \theta) \sum_{k=0}^{\infty}(\beta \theta)^{k} E_{t}\left[m c_{t+k}\right]+\sum_{k=0}^{\infty}(\beta \theta)^{k} E_{t}\left[p_{t+k}\right]
$$

Moreover, the equation (42) can be expressed in the following recursive form:

$$
p_{t}^{*}-p_{t-1}=\beta \theta E_{t}\left[p_{t+1}^{*}\right]-(1-\beta \theta) p_{t}+(1-\beta \theta) \widehat{m c}_{t}
$$


and combined with (32) in a log-linear form in order to obtain the domestic inflation equation:

$$
\pi_{t}=\beta \pi_{t+1}^{e}+\frac{(1-\theta)(1-\beta \theta)}{\theta} \widehat{m c}_{t}
$$

with $\pi_{t+1}^{e}=E_{t}\left[\pi_{t+1}\right]$.

The expression (44) states that the current value of domestic inflation is positively related to the discounted expected value of the inflation of one period ahead and to the log-deviation of real marginal cost according to the degree of price stickiness captured by the parameter $\theta$.

\section{Government}

Following the same structure of private consumption, public consumption is given by

$$
G_{t}=\left(\int_{0}^{1} G_{t}(i)^{\frac{\varepsilon-1}{\varepsilon}} d i\right)^{\frac{\varepsilon}{\varepsilon-1}}
$$

where $G_{t}(i)$ represents the quantity of domestic good $i$ purchased by the government

The Government chooses optimally the composition of a Dixit-Stiglitz aggregator over all the variety of goods produced to minimize expenditure, yielding a structure of demand schedules analogous to those of private consumption:

$$
G_{t}(i)=\left(\frac{P_{t}(i)}{P_{t}}\right)^{-\varepsilon} G_{t}
$$

Moreover, the dynamics of the aggregate public consumption is assumed to follow an $\mathrm{AR}(1)$ process (in logs):

$$
g_{t}=\varphi g_{t-1}+\epsilon_{t}^{g}
$$

where $g_{t}=\log G_{t}, \varphi \epsilon[0,1]$ is the persistence coefficient of public expenditure and $\epsilon_{t}^{g}$ is a white noise, assuming that government spending is entirely financed by means of lump-sum taxes, i.e.

$$
G_{t}=T_{t}
$$

\section{Equilibrium Dynamics}

The market clearing conditions for the good $i$ can be expressed as follows:

$$
Y_{t}(i)=C_{t}(i)+G_{t}(i)
$$


The previous relationship states that production of good $i$ can be allocated to private and public consumption.

Then, using the definitions of $C_{t}(i)$ and $G_{t}(i)$, equation (49) can be rewritten as follows:

$$
Y_{t}(i)=\left(\frac{P_{t}(i)}{P_{t}}\right)^{-\varepsilon}\left(C_{t}+G_{t}\right)
$$

Finally, by plugging (50) into the definition of the aggregate output $\left[Y_{t}=\left(\int_{0}^{1} Y_{t}(i)^{\frac{\varepsilon-1}{\varepsilon}} d j\right)^{\frac{\varepsilon}{\varepsilon-1}}\right]$, the aggregate market clearing condition is obtained:

$$
Y_{t}=C_{t}+G_{t}
$$

A first-order log-linearization of (51) around the steady state reads as

$$
\hat{y}_{t}=\lambda \hat{g}_{t}+(1-\lambda) \hat{c}_{t}
$$

where $\lambda=\frac{\bar{G}}{\bar{Y}}$ is the steady state government spending share on output.

Finally, the model is "closed" with a monetary policy Taylor rule, according to which the nominal interest rate positively reacts to the log-deviations output gap $\left(\widehat{\widetilde{y}}_{t}\right)$ and inflation $\left(\pi_{t}\right)$ :

$$
r_{t}=\phi_{\pi} \pi_{t}+\phi_{y} \widehat{\widetilde{y}}_{t}
$$

Note that, since, following the literature (Galì, 2003 and 2008), we assume a zero inflation steady state, the log-linear measure of inflation gap, i.e. the difference between the actual value of inflation and the one in the presence of fully flexible prices, coincides with the log of inflation. 